\title{
Editorial
}

\section{Sobre algunas estadísticas de esta revista}

Francisco Luis Ochoa-Jaramillo ${ }^{1 凶} \underline{\text { ORCID }}$

${ }^{1}$ Médico, magíster en Epidemiología. Profesor Universidad CES. Grupos de investigación Etices y Observatorio de la Salud Pública.

Fecha correspondencia:

Recibido: octubre 06 de 2021.

Revisado: octubre 06 de 2021

Aceptado: octubre 06 de 2021.

Forma de citar:

Ochoa-Jaramillo FL. Sobre

algunas estadísticas de esta

revista. Rev CES Med. 2021;

35(3): 211-212.

https://dx.doi.org/10.21615/

cesmedicina. 6430

\section{Open access}

C) Derecho de autor

Licencia creative commons

Ética de publicaciones

Revisión por pares

Gestión por Open Journal System

DOI: 10.21615/cesmedicina.6430

ISSNe 2215-9177

ISSN 0120-8705

Publica con nosotros
Con el fin de que tengan un panorama sobre nuestro quehacer editorial queremos presentarles algunas cifras sobre las dinámicas con los artículos que son sometidos a CES Medicina.

Así, por ejemplo, cada año recibimos en promedio 128 artículos, de los cuales se publican entre 30 y 35, es decir 10 o 12 artículos en cada número. Eso también significa que hay una importante tasa de rechazo, cerca de $75 \%$, un valor muy alto para los eventuales autores que miran con terror la elevada posibilidad de que su artículo sea rechazado; pero simultáneamente es bajo, cuando se observan los porcentajes de rechazo de otras revistas, que oscila entre 90 y $95 \%$.

En el caso de CES Medicina, como en otras publicaciones, un importante porcentaje de esos rechazos se presenta antes de que se inicie el proceso formal de revisión. ¿Las razones? Que no se cumplieron a cabalidad las instrucciones a los autores, lo cual es una condición mínima para el envío de un artículo a cualquier revista. Son requisitos "de entrada" que los autores deben respetar cuidadosamente al momento de escribir su artículo y de hacer el envío. Existe otro porcentaje del rechazo que ocurre durante las revisiones por el equipo editorial o de pares científicos, que en el primer caso se trata de asuntos formales del estilo de escritura, redacción y presentación de los mismos. Aquí recomendamos los autores que, previamente al envío de su artículo, se tomen el tiempo de revisar y leer otros trabajos ya 
publicados en la misma Revista con mirar a ajustar su texto en tales aspectos. Un refrán se ajusta perfectamente a ello: "Al pueblo que fueres, haz lo que vieres" ...

Al respecto de la revisión por los expertos, es conveniente que los autores hagan revisar previamente su texto por personas con conocimiento de la temática y acatar sus recomendaciones de mejora. Otra opción, altamente útil, es que antes de enviar su artículo a la revista, revisen las guías o formatos de evaluación que emplean los evaluadores. Si bien toda evaluación de un artículo es doble ciega, sí están disponibles en esta y en muchas otras revistas, los criterios de evaluación. Así que úselos a su favor y del artículo. 